\title{
Catchment Variability and Parameter Estimation in Multi-Objective Regionalisation of a Rainfall-Runoff Model
}

\author{
Dave L. E. H. Deckers • Martijn J. Booij • \\ Tom H. M. Rientjes • Maarten S. Krol
}

Received: 9 December 2009 / Accepted: 29 March 2010 /

Published online: 16 April 2010

(C) The Author(s) 2010. This article is published with open access at Springerlink.com

\begin{abstract}
This study attempts to examine if catchment variability favours regionalisation by principles of catchment similarity. Our work combines calibration of a simple conceptual model for multiple objectives and multi-regression analyses to establish a regional model between model sensitive parameters and physical catchment characteristics (PCCs). The objective is to test robustness of regionalisation by assessing if generalisation of a wide range of climatic, topographic and physiographic settings in a regional model favours simulation of stream flow at ungauged catchments. Constraints in this work are very stringent performance measures for selection of catchments to establish the regional model and the selection of only PCCs that are available through the database of the National River Flow Archive in the United Kingdom. As such some PCCs have been ignored that have proven to be effective in other studies. For this study 56 well-gauged catchments in England and Wales are used. For model calibration and runoff simulation of ungauged catchments the HBV model is applied. Optimum parameter sets are derived for 48 catchments through Monte Carlo Simulation using an 8-year simulation period. This study aims to adequately simulate all aspects of the hydrograph at the ungauged catchment and therefore four single objective functions are combined in a multi-objective function. After calibration, 17 catchments that are widely spread over England and Wales are selected to establish relationships for seven selected model parameters using 14 PCCs (area, mean elevation, hypsometric integral, catchment shape, standard average annual rainfall, five types of land use and four classes of hydrogeology). Single and multiple regression analysis are applied to identify these relationships. For six model parameters statistically significant relationships could be established three of which
\end{abstract}

D. L. E. H. Deckers · M. J. Booij $(\varangle) \cdot$ M. S. Krol

Water Engineering and Management, Faculty of Engineering Technology, University of Twente, P.O. Box 217, 7500 AE Enschede, The Netherlands e-mail:m.j.booij@utwente.nl

T. H. M. Rientjes

International Institute for Geo-Information Science and Earth Observation (ITC),

P.O. Box 6, 7500 AA Enschede, The Netherlands 
are plausible on the basis of hydrologic interpretation. The established relationships are validated at eight gauged catchments that are spread over the UK and cover a large range of values of catchment descriptors. These catchments are assumed ungauged and results revealed that, in general, model parameters determined by the established regional relationships do not perform better as compared to default parameter values. Similar results are obtained for additional validation runs using catchments that are not used in the regionalisation procedure. Since these parameters are based on model performance assessments in a wide range of catchment settings, this suggests that large variability in settings of PCCs does not favour regionalisation. Therefore, for selected catchments the applicability of regionalisation by principles of catchment similarity for HBV model parameters may be questioned.

Keywords England and Wales · HBV model • Multi-objective calibration • Physical catchment characteristics • Regionalisation • Ungauged catchment

\section{Introduction}

\subsection{Prediction in Ungauged Catchments}

The ability to predict flows at gauged and ungauged catchments is an important goal in hydrology. Reasons for instance are the possibilities to estimate impacts of climate or land use change on the discharge regime (see Sefton and Boorman 1997; Booij 2005; Abdulla et al. 2009) or to optimise seasonal reservoir planning for hydropower use (see Verbunt et al. 2005). For such purposes, conceptual hydrologic models are frequently used. Characteristic to these models is that only major hydrologic processes in rainfall-runoff generation are represented through simplified equations. Parameters of conceptual models commonly have no direct physical meaning and must be estimated through calibration using time series of observed discharges. Since at ungauged catchments such series are not available or of insufficient quality, estimating appropriate parameter values is far from trivial and estimation must be associated with uncertainty. Regionalisation, which is the process of transferring information from selected catchments to the catchment of interest (Blöschl and Sivapalan 1995), may serve to improve the discharge estimate at the ungauged catchment and to improve the predictive capability of the rainfall-runoff model. The relevance to improve predictive capability of models in ungauged catchments is recognized by the International Association of Hydrologic Sciences (IAHS) who adopted the topic as one of the core components for their 10-year Prediction in Ungauged Basins (PUB) project (Sivapalan et al. 2003).

\subsection{Regionalisation of Model Parameters}

In literature several regionalisation approaches are proposed but general conclusions on effectiveness cannot be drawn. The two probably most popular approaches are based on principles of similarity by spatial proximity and on similarity of catchment characteristics. The first approach is based on the rationale that catchments of close proximity have a similar flow regime since climatic, topographic and physiographic settings are comparable. The second approach is based on the assumption 
that optimised parameters representing certain catchment characteristics are also applicable in other catchments with similar characteristics. In this approach, the regionalisation of model parameters can be done using regression-type approaches and using other (physical) similarity approaches that transpose the parameter set of similar catchments (see e.g. Oudin et al. 2008). The regression-type approach is most widely tested in regionalisation studies and is also selected for this study. Besides this, regionalisation by use of default parameter sets is tested as an alternative to spatial proximity approaches.

The approach is commonly referred to as the classical approach of regionalisation and has applications in various climatic and physiographic settings. Applications are known for a number of hydrologic models such as the IHACRES model by Jakeman et al. (1990; see Sefton and Howarth 1998; Kokkonen et al. 2003), the HBV model by Bergström (1995; see Seibert 1999; Merz and Blöschl 2004; Parajka et al. 2007; Engeland and Hisdal 2009), the GR4J model (see Oudin et al. 2008) and TOPMODEL (see Ao et al. 2006), and data driven models (e.g. Cutore et al. 2007). Various studies report on the effectiveness of the classical approach, but in Merz and Blöschl (2004) and Oudin et al. (2008) the approach is outperformed by the spatial proximity approach. Zhang and Chiew (2009) found that the spatial proximity approach performs slightly better than the physical similarity approach, where in Wale et al. (2009) the opposite was found.

Sefton and Howarth (1998) used 60 catchments in England and Wales and defined relationships with correlation coefficients varying between 0.37 and 0.80 , where the selection of the relationships was based on statistical significance and hydrologic plausibility. Relationships were satisfactorily validated at two additional catchments and it was stated that relationships were robust enough to produce daily flows. For 13 sub-catchments in the Coweeta catchment in North Carolina in the USA, Kokkonen et al. (2003) described that encouraging results were achieved in reconstructing daily flows for ungauged catchments with established regression equations. It is reported that elevation, slope and mean overland flow distance are the most dominating characteristics that affect the hydrologic behaviour in these sub-catchments. In the same work it is stated that the application of multiple regression analysis does not account for model parameter dependencies and a high significance of regression does not guarantee a set of parameters to have good predictive power. Seibert (1999) used three catchment characteristics (i.e. catchment area, forest and lake percentages) of 11 Swedish catchments to relate to HBV model parameters. Relationships were found for 6 out of 13 model parameters, whereas the physical premise of some of these relationships only weakly relate to the physical basis of the hydrologic model. Not all results from the regional model were satisfactory and some results could be questioned. More recent work by Young (2006) who used the Probability Distributed Model (PDM) toolkit (Moore 1985, 1999) and Wagener and Wheater (2006) using the Rainfall Runoff Modelling Toolbox (RRMT; Wagener et al. 2002) in the UK showed that regionalisation was not successful in all cases. Our work differs from the previous work in a manner that we aim to evaluate the effectiveness of the regional model for multiple objectives. In Wagener and Wheater (2006) the focus is much more on issues that relate to model identification. Our work more resembles the works by Kay et al. (2006), Young (2006) and Oudin et al. (2008) that generally aim to evaluate effectiveness of regionalisation by considering multiple objectives and/or effects of parsimonious model structures. 
Principle to the catchment similarity approach is that, at first, model parameter values need to be estimated for gauged catchments through model calibration that basically bears down to the application of a parameter optimization procedure. Such calibration is far from trivial and during the nineties a wide consensus has been reached that almost equally good simulation results can be obtained with parameter sets that may have very different locations in parameter space (e.g. Beven and Binley 1992; Jakeman and Hornberger 1993; Seibert 1997). The problem to optimally identify parameter values causes that parameter values are uncertain. For this reason Beven and Binley (1992) abandoned the principle of uniquely identifiable parameter sets and introduced the concept of equifinality, i.e. many different parameter sets within a chosen model structure may be behavioural or acceptable in reproducing the observed hydrological behaviour. Obviously, the identifiability problem also impacts regionalisation studies since it constrains to adequately express model parameters as functions of physical catchment characteristics (PCCs). To overcome the problem to well identify parameters, Wagener et al. (2003) proposed the use of parsimonious model structures while Gupta et al. (1998) advocated the application of a multiobjective function to extract more information from time series of observed flow. Principle to such approach is that selected objective functions must assess different aspects of the hydrograph, see also Tang et al. (2006), De Vos and Rientjes (2007) and Gupta et al. (2008).

\subsection{Scope of the Paper}

In this study the effectiveness of multi-objective (MO) model calibration in regionalisation has been assessed. Hundecha and Bárdossy (2004), Seibert (1999), Parajka et al. (2007), Yadav et al. (2007) and Oudin et al. (2008) report on MO applications and focussed on assessing two or more characteristics of the stream flow hydrograph (e.g. average, low and high flows). In this study relationships will be established to estimate parameter values at the ungauged catchment that predict average, low and high flows while also the error in the water balance is evaluated.

The objective of this study is to assess the predictive capability of a regionalisation procedure based on MO calibration of the HBV model and to explore effectiveness of multiple linear regression analysis to establish relations between model sensitive parameters and selected PCCs. Runoff from the ungauged catchments will be simulated by the HBV model as well, where parameter values are estimated by the regional relationships. The classical approach of regionalisation is applied to 56 well-gauged catchments in England and Wales. Besides MO calibration, this study differs from many studies by use of very stringent model performance criteria for selection of calibration catchments and by use of only PCCs that are available in the public domain. Moreover, the intention is to establish relationships which are able to estimate parameters for the ungauged catchments that can adequately predict different aspects of the hydrograph.

This paper is organised as follows. In Section 2 the study area and data are presented. The applied methodology is described in Section 3 which is divided in four sub-sections: the rainfall-runoff model, the calibration of the rainfall-runoff model, the establishment of the regional relationships and the validation of the regional relationships. Hereafter, in Section 4 the results are described, in Section 5 the results are discussed and in Section 6 conclusions are drawn. 


\section{Study Area and Data Description}

The study area covers 56 well gauged catchments which are well distributed throughout England and Wales (see Fig. 1). For simulation of runoff with the HBV model, time series of precipitation, actual temperature and potential evapotranspiration are required for all catchments. For calibration of the model also time series of observed runoff are required. The daily mean runoff (cubic meter per second) and daily catchment average precipitation (millimeter) are obtained for the period 1983-1990 from the Data60UK dataset (Data60UK 2009). This dataset has undergone extensive analysis as reported in previous studies (e.g. Jakeman et al. 1990; Jakeman and

$\triangle$ Calibration catchments

- Validation catchments

- Non-satisfying catchments
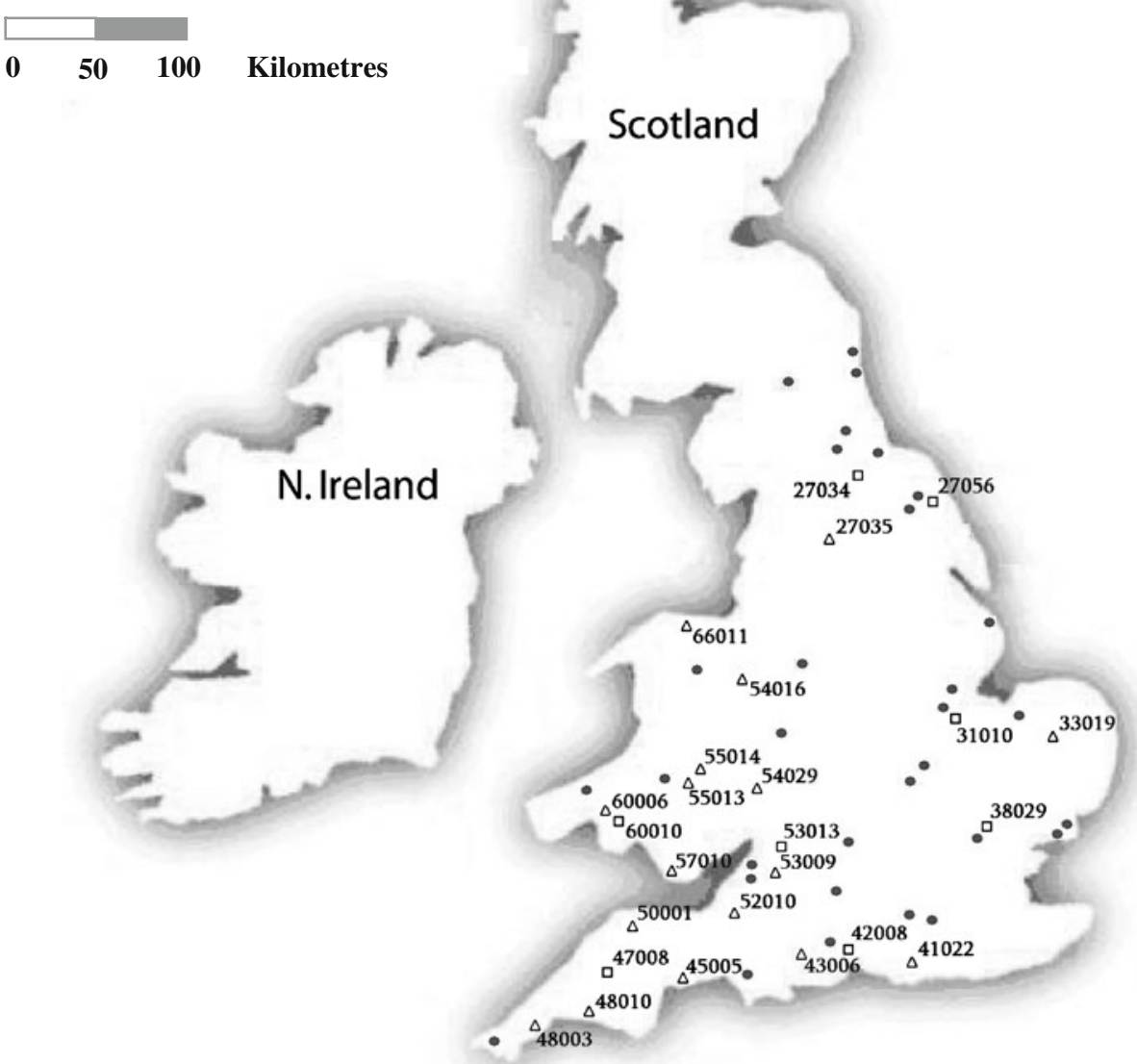

Fig. 1 Study area with distribution of 17 calibration catchments, 8 validation catchments and 31 non-satisfying catchments (NS $<0.75$ and $|\mathrm{RVE}|>5 \%$ ) 
Hornberger 1993; Sefton and Howarth 1998). The study area includes moderately dry up to wet catchments since the average annual rainfall over the period 19831990 ranges from less than $600 \mathrm{~mm}$ in east England to more than 2,100 $\mathrm{mm}$ in Wales. Daily potential evapotranspiration has been estimated based on the formula of Penman-Monteith, as recommended by the Meteorological Office for general use in the United Kingdom (Shaw 1994). This formula requires time series of actual temperature, dew point temperature, sunshine hours and wind speed. These are obtained from observation stations throughout the United Kingdom originating from the British Atmospheric Data Centre (BADC 2009). For estimation of potential evapotranspiration the two nearest observation stations which hold the datasets for actual temperature, dew point temperature and wind speed are used while for sunshine hours only the closest observation station is used. For the required daily temperature, the same dataset is used as generated for estimation of the daily potential evapotranspiration.

By the constraint to only use data that are available in the public domain, for derivation of PCCs-the database of the National River Flow Archive (NRFA 2009) is used that is linked to the Catchment Spatial Information website (CSI 2009). It must be noted that by our selection the use of effective PCCs such as the Base Flow Index (BFI) from the HOST data base is denied. BFIHOST for instance is successfully used in Young (2006) and Wagener and Wheater (2006). For selection of PCC values, the boundaries of the catchments are based on regional topographic boundaries compiled through use of the Integrated Hydrological Digital Terrain Model (IHDTM) from the Centre for Ecology and Hydrology (CEH). Elevation is also derived by application of the IHDTM which has a $50 \mathrm{~m}$ horizontal resolution with an elevation accuracy of $0.1 \mathrm{~m}$. This resulted in catchments with sizes that vary from 25 up to $1,480 \mathrm{~km}^{2}$, where most catchments have an average elevation between 100 and $200 \mathrm{~m}$ a.m.s.l. with 25.3 and $430.6 \mathrm{~m}$ a.m.s.l. as lowest and highest values in the dataset. Land use maps are derived from the Land Cover Map 2000 which is part of the Countryside Survey 2000 and 27 categories are identified. At the CSI pages these are grouped into seven classes. In most catchments the dominating land use class is 'grassland' with an average of $42.6 \%$, followed by 'arable' and 'woodland' with values of respectively $30.4 \%$ and $13.4 \%$. Geological maps are derived from the $1: 625,000$ British Geological Survey datasets. A dataset with hydrogeological characteristics that affect river flow behaviour is used to make a distinction between permeable and impermeable bedrock. In total, six classes are defined from impermeable bedrock to highly permeable bedrock. Wales generally contains very low permeable bedrock whereas south, southeast and west England predominantly contain highly permeable bedrock.

\section{Methodology}

\subsection{Hydrologic Model}

The conceptual hydrologic model HBV is selected considering that it has many applications in operational and strategic water management. The model has successfully been applied to catchments of various sizes and in a large range of geographic and climatic settings. Applications in regionalisation studies are reported by, for instance, Seibert (1999), Merz and Blöschl (2004), Booij (2005) and Wale et al. (2009). The 
Table 1 Model parameters and their minimum and maximum values used in the Monte Carlo simulation

\begin{tabular}{|c|c|c|c|}
\hline Parameter & Description & Minimum & Maximum \\
\hline$\overline{\mathrm{FC}}$ & Maximum soil moisture storage $(\mathrm{mm})$ & 125 & 800 \\
\hline BETA & Parameter of power relationship to simulate indirect runoff $(-)$ & 1 & 4 \\
\hline LP & $\begin{array}{l}\text { Limit above which evapotranspiration reaches its potential } \\
\text { value }(-)\end{array}$ & 0.1 & 1 \\
\hline ALFA & Measure for non-linearity of flow in quick runoff reservoir $(-)$ & 0.1 & 3 \\
\hline $\mathrm{K}_{\mathrm{f}}$ & $\begin{array}{l}\text { Recession coefficient for runoff from quick runoff reservoir } \\
\text { (per day) }\end{array}$ & 0.0005 & 0.15 \\
\hline $\mathrm{K}_{\mathrm{s}}$ & $\begin{array}{l}\text { Recession coefficient for runoff from base flow reservoir } \\
\text { (per day) }\end{array}$ & 0.0005 & 0.15 \\
\hline PERC & $\begin{array}{l}\text { Constant percolation rate occurring when water is available } \\
\left(\mathrm{mm} \text { day }^{-1}\right)\end{array}$ & 0.1 & 2.5 \\
\hline
\end{tabular}

model simulates river discharge and requires precipitation, actual temperature and potential evapotranspiration as input. The HBV-96 model version (Lindström et al. 1997) is used with a fixed time step of one day and in a spatially lumped way. The model used in this study consists of four routines, which are a precipitation accounting routine, a soil moisture routine, a quick runoff routine and a base flow routine which together transform excess water from the soil moisture zone into local runoff. A full description of the HBV model is ignored for reasons of brevity and the reader is referred to Lindström et al. (1997) and SMHI (1999). In Table 1 a description of the model parameters is given.

The classical approach of regionalisation is applied and consists of three steps. First the HBV model is calibrated for 48 gauged catchments against observed discharge in order to determine a well performing parameter set. Secondly, relationships between sensitive model parameters and PCCs are established that make up the so called 'regional model' and serves to estimate model parameters for the ungauged catchments. Thirdly the HBV model is used to validate the regional model for the remaining eight ungauged catchments. In the following three sub-sections a description of the three steps is given.

\subsection{Calibration}

\subsubsection{Calibration and Selection of Parameters}

For calibration of the HBV model Monte Carlo simulation (MCS) is applied to 48 catchments. In MCS, simulations are executed for a large number of randomly generated parameter sets that are within a pre-defined parameter space. Model performance assessment is evaluated through an objective function or measure that is an expression of fit between observed and simulated runoff hydrographs. Most important in MCS is the selection of model calibration parameters, the determination of prior parameter space, the selection of probability distributions for the calibration parameters, the determination of the number of simulations to be executed and the selection of the objective function(s). For first applications of MCS simulation in hydrology we refer to Beven and Binley (1992) and Harlin and Kung (1992).

In this study we aim to develop a procedure that allows for simulation of various aspects of the hydrograph. Therefore, a selection of HBV model parameters has to be made that are sensitive to the various aspects. In studies by for instance Harlin and 
Kung (1992), Lindström et al. (1997), Seibert (1999) and Booij (2005) such sensitivity is demonstrated and results of these studies are used for selection of model calibration parameters. As such seven parameters are selected that require optimisation while for the remaining model parameters default values are used following SMHI (1999). The transformation routine that smoothes the instant runoff contributions and the routing routine for linkage of upstream catchments are omitted.

Model parameter space is determined by evaluating model parameter ranges applied in HBV studies by Bergström (1990), Booij (2005), Diermanse (2001), Harlin and Kung (1992), Killingtveit and Sælthun (1995), Lidén and Harlin (2000), Seibert (1999), SMHI (1999) and Velner (2000). Parameter values are randomly and independently sampled from uniform distributions. In Table 1 the selected model parameters and parameter ranges are given. For examination of the prior space of calibration parameters we selected a simulation run number of 10,000 (see also Wagener and Wheater 2006).

\subsubsection{Selection of Objective Functions}

Madsen (2000) stated that for evaluation of a calibrated model usually four different objectives are considered. These are (1) a good water balance, (2) a good overall agreement of the shape of the hydrograph, (3) a good agreement of high flows and (4) a good agreement of low flows. In this work, for each of these objectives a (single) objective function (SOF) is defined that are the relative volume error $\left(R V_{\mathrm{E}}\right)$ for assessing the goodness of fit for the water balance and the Nash-Sutcliffe coefficient (NS) (Nash and Sutcliffe 1970) for overall fit and high and low flows. The four objective functions are:

$$
\begin{gathered}
R V_{E}=\left(\frac{\sum_{i=1}^{n} Q_{\text {sim }(i)}-\sum_{i=1}^{n} Q_{o b s(i)}}{\sum_{i=1}^{n} Q_{o b s(i)}}\right) \cdot 100 \% \\
N S=1-\frac{\sum_{i=1}^{n}\left(Q_{\text {sim }(i)}-Q_{o b s(i)}\right)^{2}}{\sum_{i=1}^{n}\left(Q_{o b s(i)}-\overline{Q_{o b s(i)}}\right)^{2}} \\
N S_{H}=1-\frac{\sum_{i=1}^{n} Q_{o b s(i)} \geq Q_{\text {high }}\left(Q_{\text {sim }(i)}-Q_{o b s(i)}\right)^{2}}{\sum_{i=1}^{n} Q_{o b s(i)} \geq Q_{h i g h}\left(Q_{o b s(i)}-\overline{Q_{o b s, h i g h(i)}}\right)^{2}} \\
N S_{L}=1-\frac{\sum_{i=1}^{n} Q_{o b s(i)} \leq Q_{t o w}\left(Q_{\operatorname{sim}(i)}-Q_{o b s(i)}\right)^{2}}{\sum_{i=1}^{n} Q_{o b s(i)} \leq Q_{l o w}\left(Q_{o b s(i)}-\overline{Q_{o b s, l o w(i)}}\right)^{2}}
\end{gathered}
$$

where $Q_{s i m}$ stands for simulated flow, $Q_{o b s}$ for observed flow, $\overline{Q_{o b s(i)}}$ for the average of observed flow, $\overline{Q_{o b s, h i g h(i)}}$ for the average of observed flow above the selected high 
discharge threshold $Q_{h i g h}, \overline{Q_{o b s, l o w(i)}}$ for the average observed flow below the low discharge threshold $Q_{\text {low }}, i$ for the time step and $n$ for the total number of time steps used during calibration. $R V_{\mathrm{E}}$ varies between $-\infty$ and $\infty$ but performs best when a value of 0 is generated. $N S, N S_{\mathrm{H}}$ and $N S_{\mathrm{L}}$ vary between $-\infty$ and 1 and perform best when a value of 1 is generated. Negative $N S$ values indicate that the observed mean discharge is a better predictor than the model simulation. The simulation period is from January 1, 1983 to December 31, 1990. The first 8 months are selected as warmup period and have not been used to calculate the SOF values. Threshold values for low and high flow are arbitrarily defined as the 5-percentile and 90-percentile of exceeding probabilities. Selected percentiles suggest clear differentiation for the various catchment response modes that cause high and low flows.

\subsubsection{Combination of Objective Functions}

For the past decade, research on multi-objective model calibration revealed that trade-offs exist between the different objectives and that, for instance, parameter sets that yield good results for high flows may yield poor results for low flows. To adequately simulate the different aspects of the stream flow hydrograph, trade-offs must be evaluated to arrive at a well performing and robust parameter set that for selected objectives optimally performs. In this study a multi-objective function (MOF) is defined by combining all four SOFs. In the procedure each SOF contributes equally to the parameter optimisation problem where objective functions require rescaling to allow for evaluation. Such evaluation should aim at selection of a parameter set that performs well for all SOFs. The likeliness that a parameter set with highest performance for one SOF also performs best for a second SOF of a different nature is questionable (see De Vos and Rientjes 2008). Therefore in this study we do not aim to select a best performing parameter set for one of the objectives but simply a parameter set that, presumably, performs well for all four selected performance measures. We hypothesize that such parameter set can be found in the selection of $10 \%$ best performing parameter sets after rescaling. Alternatively, a non-preference based multi-objective method can be used that independently optimises multiple objectives and reveals a set of solutions that represent the trade-off between the objectives involved (i.e. a Pareto front, see e.g. Yapo et al. 1998; Khu and Madsen 2005). The MOF used in this study implicitly balances the SOFs, which is in contrast to Pareto optimisation, where this is not necessary.

In this study for each catchment and for each SOF, the 1,000 best performing sets were used for rescaling. The best objective function value is the maximum $N S, N S_{\mathrm{H}}$ and $N S_{\mathrm{L}}$ value and the minimum absolute $R V E$ value out of 10,000 runs. The worst objective function value is the 1,000th best calibration run for each SOF out of 10,000 runs. For $N S, N S_{\mathrm{H}}$ and $N S_{\mathrm{L}}$, for each calibration run the difference between the calculated and the worst objective function value is divided by the difference between the best and worst objective function values. For $R V E$., for each calibration run the difference between the absolute values of the calculated and the best objective function values is divided by the difference between the absolute values of the worst and best objective function values. Consequently, out of the 10,000 runs, rescaling of the SOF values resulted for the 1,000th best calibration run (worst objective function value) in a value of 0 and for the best calibration run (best objective function value) in a value of 1 . This implies that $90 \%$ of the 10,000 rescaled SOF values will be negative. For each run the minimum rescaled SOF value is selected out of the group of four 
rescaled SOFs as expressed in Eq. 5 and is referred to as the minimum rescaled value $\mathrm{C}^{\prime}{ }_{m}$.

$$
C_{m}^{\prime}=\operatorname{Min}\left(C_{S-N S, m}, C_{S-N S_{H}, m}, C_{S-N S_{L}, m}, C_{S-R V_{E}, m}\right)
$$

where $C_{S}$ stands for the rescaled SOF value and $m$ for the calibration run number. For development of the regional model, the optimum parameter set $C_{o p t}$ is now defined by selecting the maximum of the rescaled values $C_{m}^{\prime}$ :

$$
C_{o p t}=\operatorname{Max}\left(C_{m}^{\prime} \mid 1 \leq m \leq 10000\right)
$$

The selected parameter set is to be interpreted as a well performing or well behaving 'single best' parameter set that, we hypothesise, is suitable for the development of the regional model. The above procedure differs from works by Wagener and Wheater (2006), Young (2006) and Parajka et al. (2007) since its optimisation is independent for all four functions. In this respect our approach may be considered more pragmatic since the final selection of the rescaled optimally performing parameter set is only dependent on a single objective that may be different for the various catchments. While for one catchment $N S$ may be highest for another catchment this may be $N S_{\mathrm{H}}$, $N S_{\mathrm{L}}$ or $R V_{\mathrm{E}}$. Principle to the approach is that we simply select a well performing parameter set for any one catchment that as such carries sufficient information to act as a descriptor of dominant hydrological characteristics of the catchment.

\subsection{Establishing the Regional Model}

The aim in determining the regional model is to establish statistically and hydrologically relevant relationships between model parameters and PCCs. To achieve this, selections have to be made for the calibrated catchments to be used for establishing the regional model and for the PCCs to be considered.

For the selection of calibration catchments two conditions are introduced: $N S>$ 0.75 and $\left|R V_{\mathrm{E}}\right|<5 \%$. We only used $N S$ and $R V_{\mathrm{E}}$ because these criteria have been used in many other studies and allowed to reasonably define thresholds. Both conditions indicate that a model performs very well, although a high performance indicator not (automatically) means that a model performs equally well on a catchment with limited flow variation as compared to a catchment with highly variable flows. It is noted that fulfilling both criteria has severely constrained the selection of catchments. For instance, preliminary results indicated that a NS larger than 0.6 would result in some 35 out of 48 catchments. In many regionalisation studies (see e.g. Merz and Blöschl 2004; McIntyre et al. 2005; Young 2006; Duan et al. 2006; Parajka et al. 2007; Oudin et al. 2008) the use of stringent criteria is advocated since such, presumably, allows selection of only those catchments for which a robust regional model could be established. It is noted, however, that criteria in the previous works are much more relaxed and commonly a NS efficiency of only 0.6 to 0.7 is used. Also, in Oudin et al. (2008) it is reported that poorly described catchments do not provide sufficient relevant information. This has motivated our selection to apply the stringent performance criteria. Our selection has resulted in 17 catchments suitable for establishing the regional model while 31 catchments are rejected. Relaxing the $N S$ and $R V_{\mathrm{E}}$ criteria would result in a much larger group of catchments suitable for further use but, expectedly, also would result in introducing a wider range of catchment settings to the regional model. We note that this aspect of selecting 
catchments for establishing the regional model touches on the (principle) discussion on effectiveness of regionalisation by the classical method but is further addressed in Section 5.

Selection of PCCs is based on previous research on regionalisation using HBV (i.e. Seibert 1999; Hundecha and Bárdossy 2004; Merz and Blöschl 2004) and the IHACRES model for catchments in England and Wales (Sefton and Howarth 1998) and on the availability of the data on PCCs in the public domain. This resulted in the selection of 14 PCCs, classified into six groups as shown in Table 2. The PCC $H I$ is a measure of the distribution of elevation in a catchment and is defined as the average elevation a.m.s.l. minus the minimum divided by the difference between the maximum and minimum elevation a.m.s.l. SHAPE is defined as the difference between the maximum and minimum elevation a.m.s.l. divided by the square root of catchment size. Some statistics for each PCC and the average discharge, annual rainfall and annual potential evapotranspiration are shown in Table 3 and indicate wide ranges of climatic, topographic, geologic and land use settings. Whether this variability favours regionalisation could be questioned. This issue is also briefly addressed in Young (2006) and will be further discussed in Section 5.

For establishing relationships between model parameters and PCCs a simple correlation analysis has been performed with a significance level of $\alpha=0.1$. Scatter plots between model parameters and PCCs are evaluated to analyse non-linearity of relationships and regression analyses are performed in which the forward entry method and the backward removal method are applied. In the forward entry method, the established significant single relationships are extended by forcing additional PCCs in the relationships until the last added PCC does not significantly contribute to the relationship. In the backward removal method, relationships incorporate all PCCs after which these ones are stepwise reduced until a significant relationship is determined. Hereafter, the single and multiple relationships for each model parameter are evaluated from a hydrological point of view since statistically significant relationships could possibly lack physical explanation. Finally, for each model parameter a relationship is selected with one or more $\operatorname{PCC}(\mathrm{s})$, based on the statistical significance (correlation coefficient of the relationship $r$ ) and on hydrologic

Table 2 Selected physical catchment characteristics (PCCs)

\begin{tabular}{|c|c|c|}
\hline Group & PCC & Description \\
\hline Dimension & AREA & Catchment size $\left(\mathrm{km}^{2}\right)$ \\
\hline \multirow[t]{2}{*}{ Topography } & ELEVATION & Catchment average elevation (m.a.s.l.) \\
\hline & $\mathrm{HI}$ & Hypsometric integral $(-)$ \\
\hline Shape & SHAPE & Catchment shape $(-)$ \\
\hline \multirow[t]{5}{*}{ Land use } & Wood & Woodland (\%) \\
\hline & Arable & Arable and horticulture (\%) \\
\hline & Grass & Grassland (\%) \\
\hline & Mountain & Mountain, heath and bog $(\%)$ \\
\hline & Urban & Built-up areas (\%) \\
\hline \multirow[t]{4}{*}{ Geology and soils } & HIGHP & High permeability of bedrock (\%) \\
\hline & MODERATEP & Moderate permeability of bedrock (\%) \\
\hline & LOWP & Very low permeability of bedrock (\%) \\
\hline & MIXEDP & Mixed permeability of bedrock (\%) \\
\hline Climate & SAAR & Standard annual average rainfall ( $\mathrm{mm})$ \\
\hline
\end{tabular}


Table 3 Statistics for each physical catchment characteristic (PCC) and average discharge $(Q)$, annual rainfall $(P)$ and annual potential evapotranspiration (PET) over the period 1983-1990

\begin{tabular}{llccccc}
\hline PCC/variable & Unit & Minimum & 25 Percentile & Median & 75 Percentile & Maximum \\
\hline AREA & km $^{2}$ & 24.5 & 59.2 & 125.4 & 247.9 & 1480.0 \\
ELEVATION & m.a.s.l. & 25.3 & 116.3 & 141.1 & 215.5 & 430.6 \\
HI & - & 0.21 & 0.34 & 0.39 & 0.45 & 0.68 \\
SHAPE & - & 1.99 & 8.89 & 13.82 & 20.42 & 50.47 \\
Wood & $\%$ & 1.2 & 7.6 & 12.0 & 16.1 & 49.1 \\
Arable & $\%$ & 0.1 & 6.2 & 29.5 & 48.9 & 80.0 \\
Grass & $\%$ & 9.8 & 28.9 & 40.5 & 59.0 & 81.0 \\
Mountain & $\%$ & 0 & 0.4 & 1.8 & 7.3 & 63.6 \\
Urban & $\%$ & 0.2 & 1.8 & 3.2 & 6.1 & 74.0 \\
HIGHP & $\%$ & 0 & 0 & 0 & 53.0 & 100 \\
MODERATEP & $\%$ & 0 & 0 & 0 & 37.9 & 100 \\
LOWP & $\%$ & 0 & 0.7 & 42.5 & 84.0 & 100 \\
MIXEDP & $\%$ & 0 & 0 & 0 & 4.5 & 25.1 \\
Q & $\mathrm{m}^{3} \mathrm{~s}^{-1}$ & 0.2 & 0.6 & 1.5 & 3.0 & 38.6 \\
SAAR $=$ P & $\mathrm{mm} \mathrm{year-}^{-1}$ & 573 & 703 & 825 & 1,175 & 2.173 \\
PET & $\mathrm{mm} \mathrm{year}^{-1}$ & 570 & 635 & 654 & 679 & 751 \\
\hline
\end{tabular}

reasoning of the relationship. From this procedure only four PCCs $(H I, H I G H P$, $L O W P$ and $S A A R$ ) could be identified that have significant effect on the established parameter set.

\subsection{Validation}

The regional model is validated based on the proxy-basin test (see Klemeš 1986) and eight gauged catchments are considered as pseudo ungauged. The established regional model is applied to these validation catchments for which model parameter sets are generated. Out of 56 catchments, we selected eight catchments with significant hydrologic, climatic and physiographic diversity and distribution over the entire study area. For each of the four PCCs (i.e. HI, HIGHP, LOWP and SAAR) for which we assume they have a clear effect on runoff generation, we selected two validation catchments that have PCC values closest to the 10-percentile and 90percentile.

Performance of the regional model is assessed through the four non-scaled SOF values and by comparison of the four non-scaled SOF values of the regional parameter set, a default parameter set and an optimum parameter set. For determination of the optimum parameter set for the validation catchments the MCS methodology as used for the calibration catchments is applied. The default parameter set uses the default values from SMHI (1999). It is noted that the default set must be interpreted as a generic descriptor of runoff behaviour for a wide range of climatic, topographic and physiographic settings. We denied establishing a default set as based on median values of selected parameters (see e.g. Parajka et al. 2007; Oudin et al. 2008) since the default set suggests universal applicability. For missing default parameter values the average over the minimum and maximum values used in other research (i.e. the same nine studies as used for determining the parameter space) are calculated. The essence of comparing the performance of the regional parameter set to the default parameter set is that the latter set will be used for application in ungauged catchments if the regional model fails to produce a realistic parameter set. To our knowledge such has 
not been demonstrated before, but results in this work proved that the comparison was very effective to assess predictive capability of the regional model.

\section{Results}

\subsection{Calibration}

Following the calibration procedure a number of parameters could be well identified since the model performed well within relatively small parameter space. The nonscaled SOF values for the optimum parameter sets for the 17 calibration catchments are shown in Table 4. Note that negative values are generated for the SOFs $N S_{\mathrm{H}}$ and $N S_{\mathrm{L}}$ for respectively 2 and 15 catchments and indicate that the HBV model has difficulty in simulating low flow behaviour for these UK catchments (see Fig. 1). It is noted that in $N S_{\mathrm{L}}$ the error of the model is compared to the variance of observed low flows. Since low flows generally have a very low variance, it is difficult to obtain small model errors compared to the observed variance, which often yields negative criterion values.

Results also revealed that calibration for catchments with $S A A R<800 \mathrm{~mm}$ (i.e. dry catchments) failed since $N S>0.75$ and $\left|R V_{\mathrm{E}}\right|<5 \%$ criteria have not been met. Also the mountainous catchments (Mountain $>17 \%$ ) fail the calibration conditions which are practically all situated in the northern part of England. Furthermore, the catchment with an exceptionally large built-up area $($ Urban $=61.3 \%)$ also failed the conditions. For 18 out of the 31 non-satisfying catchments $N S$ values above 0.6 were obtained. For 15 out of the 31 non-satisfying catchments it was possible to obtain $N S$ values larger than 0.75 . Thus, in a single objective perspective, the performance of the model is actually overestimated when only considering the NS coefficient as performance indicator, but also it could indicate that $R V_{\mathrm{E}}$ is more restrictive than NS.

Table 4 Seventeen calibration catchments with non-scaled single objective function values

\begin{tabular}{llrrr}
\hline Catchment & $N S(-)$ & $R V_{\mathrm{E}}(\%)$ & $N S_{\mathrm{H}}(-)$ & $N S_{\mathrm{L}}(-)$ \\
\hline 27035 & 0.82 & -1.10 & -0.10 & -1.86 \\
33019 & 0.75 & 1.54 & 0.38 & -5.85 \\
41022 & 0.76 & 0.16 & 0.73 & -3.64 \\
43006 & 0.80 & -1.30 & 0.72 & -19.72 \\
45005 & 0.78 & -0.47 & 0.53 & -73.59 \\
48003 & 0.87 & -0.75 & 0.37 & -3.27 \\
48010 & 0.94 & -1.33 & 0.57 & -3.60 \\
50001 & 0.81 & -0.40 & -2.24 & -1.13 \\
52010 & 0.78 & -4.14 & 0.60 & -12.93 \\
53009 & 0.88 & -4.02 & 0.67 & -12.38 \\
54016 & 0.79 & -1.91 & 0.36 & -1.79 \\
54029 & 0.82 & -1.53 & 0.54 & -0.66 \\
55013 & 0.84 & 0.99 & 0.63 & -3.46 \\
55014 & 0.89 & -0.51 & 0.65 & -1.51 \\
57010 & 0.88 & 0.66 & 0.16 & 0.33 \\
60006 & 0.85 & -2.11 & 0.61 & 0.63 \\
66011 & 0.80 & -4.20 & -0.01 & -0.04 \\
\hline
\end{tabular}

Catchment numbers correspond with catchment observation stations as maintained at the National River Flow Archive 


\subsection{Establishing the Regional Model}

The correlation analyses resulted in significant correlations for 9 out of 98 relationships between model parameters and PCCs (Table 5). The strongest correlation exists between evapotranspiration parameter $L P$ and annual average rainfall $S A A R$ although such could be questioned from a hydrological point of view since SAAR only is defined at an annual scale thus ignoring the seasonal precipitation distribution while LP much more reflects on (actual) antecedent precipitation conditions. An almost equally strong positive correlation is found between percolation parameter PERC and hypsometric integral HI-, that is justifiable based on Strahler (1952) and Merz and Blöschl (2004). For the quick recession coefficient $K_{\mathrm{f}}$ a considerably weaker negative correlation is found with $H I$ although a relation between the two can be reasoned for. The remaining significant six correlations all concern model parameter BETA related to indirect runoff. Three of these correlations relate to the PCC group land use, whereas the other three relate to respectively ELEVATION, $S A A R$ and $H I G H P$ (high permeability of bedrock).

Next, multiple regression analyses were performed. At first, multiple land use classes were combined in a multiple regression equation and a relationship could be established for BETA. Through the forward entry method it was proved that the best correlation could be established when land use classes Arable and Urban were used. Application of the backward removal method did not lead to improvements in estimating BETA.

For parameter $F C$ (maximum soil moisture storage) a significant relationship could be established by considering the PCCs Arable and HIGHP. In this relation higher values for $H I G H P$ resulted in a decrease of the maximum soil moisture storage that is consistent with storage characteristics of bedrock material. Concerning parameter $A L F A$, determining the non-linearity of flow in the quick runoff reservoir, the multiple regression analysis resulted in only a significant relationship with the PCCs ELEVATION, HI and LOWP (very low permeability of bedrock). However, the hydrologic plausibility of the total relationship is questioned since the correlation with ELEVATION and $H I$ could not be explained. Regarding parameter $K_{\mathrm{f}}$ the

Table 5 Correlations between physical catchment characteristics and model parameters

\begin{tabular}{lrrrrrrr}
\hline & \multicolumn{1}{c}{ FC } & BETA & \multicolumn{1}{c}{ LP } & \multicolumn{1}{c}{ ALFA } & \multicolumn{1}{c}{$\mathrm{K}_{\mathrm{f}}$} & \multicolumn{1}{c}{$\mathrm{K}_{\mathrm{s}}$} & PERC \\
\hline AREA & -0.12 & 0.20 & -0.12 & -0.13 & 0.08 & 0.11 & 0.01 \\
ELEVATION & -0.20 & 0.49 & 0.16 & -0.32 & 0.37 & 0.26 & -0.08 \\
HI & 0.14 & -0.08 & -0.03 & 0.41 & -0.44 & -0.41 & 0.64 \\
SHAPE & -0.03 & 0.10 & 0.26 & -0.13 & 0.14 & -0.07 & 0.03 \\
SAAR & -0.04 & 0.48 & 0.65 & -0.03 & 0.38 & 0.20 & -0.20 \\
Wood & -0.01 & -0.04 & -0.10 & 0.29 & -0.13 & 0.30 & -0.05 \\
Arable & 0.21 & -0.57 & -0.31 & 0.09 & -0.33 & -0.37 & 0.21 \\
Grass & -0.29 & 0.59 & 0.31 & -0.20 & 0.33 & 0.235 & -0.17 \\
Mountain & 0.16 & 0.33 & 0.10 & -0.06 & 0.08 & 0.189 & -0.12 \\
Urban & 0.17 & -0.49 & 0.11 & -0.03 & 0.23 & -0.303 & 0.08 \\
HIGHP & -0.07 & -0.42 & -0.23 & 0.06 & -0.23 & -0.147 & 0.13 \\
MODERATEP & -0.15 & -0.08 & 0.21 & -0.26 & 0.37 & 0.152 & -0.14 \\
LOWP & 0.16 & 0.37 & 0.05 & 0.21 & -0.11 & 0.037 & -0.05 \\
MIXEDP & 0.12 & 0.06 & -0.27 & -0.05 & -0.25 & -0.244 & 0.34 \\
\hline
\end{tabular}

Values in italics are significant 
Table 6 Selected relationships for definition of the regional model

\begin{tabular}{lll}
\hline Parameter & Relationship & Correlation, $r$ \\
\hline$F C$ & $1 /(0.0054-0.000105 \times$ Arable $+0.0006685 \times H I G H P)$ & 0.64 \\
BETA & $3.244-0.02328 \times$ Arable $-0.09863 \times$ Urban & 0.67 \\
$L P$ & $\mathrm{LN}(1.568+0.000630 \times$ SAAR $)$ & 0.69 \\
ALFA & $-0.06649-0.00155 \times$ ELEVATION $+1.652 \times H I+$ & 0.65 \\
& $0.00350 \times$ LOWP & 0.75 \\
$\mathrm{~K}_{\mathrm{f}}$ & $0.05866+0.000347 \times$ ELEVATION $-0.274 \times \mathrm{HI}+$ & \\
& $0.00775 \times$ Urban & - \\
$\mathrm{K}_{\mathrm{s}}$ & 0.0315 & 0.64 \\
PERC & $-0.595+5.615 \times H I$ & \\
\hline
\end{tabular}

Model parameters in italics are (partially) questioned based on hydrological interpretation

PCCs ELEVATION and Urban are added to the significant correlation with $H I$, together forming the strongest and most significant relationship which also is hydrologically plausible. For parameter PERC the multiple regression analysis resulted in a relationship with several PCCs but, hydrologically, this relation can be questioned.

After evaluation of the established significant single and multiple regression equations, for each model parameter the most plausible relationship is selected based on hydrologic reasoning and common understanding on the range of aspects that affects catchment runoff behaviour. These are shown in Table 6, in which the relationships belonging to the model parameters in italics are somehow questionable from a hydrologic point of view. For 6 out of 7 model parameters a relationship could be determined, whereas for the base flow parameter $K_{\mathrm{s}}$ no statistically significant relationship was found. As a consequence and for simulating discharge at the validation catchments, the default value for $K_{\mathrm{s}}$ is used. For parameter $P E R C$ single regression favoured multiple regression and as such $P E R C$ only will be related to $H I$ in predicting runoff from ungauged catchments.

\subsection{Validation}

Application of the regional model to the validation catchments showed some outcomes that make the regionalisation approach in this study open to discussion. For instance it proved that some PCC values are outside the defined PCC space but also that some calculated model parameter values are outside the defined parameter space. Especially for parameter $F C$ lower values are calculated than the minimum value and for 4 out of 8 validation catchments values lower than $60 \mathrm{~mm}$ are generated. For parameter $K_{\mathrm{f}}$ negative values are calculated for two catchments. This can be partly contributed to the fact that some regression relationships are questionable from a hydrologic point of view (e.g. for $F C$ ). In this work, the actual PCC or calculated parameter value is replaced by the minimum or maximum PCC or parameter value if respective values lay outside PCC space or model parameter space. The applied conditions resulted in adjusting 11 model parameter values for 6 out of 8 validation catchments. Only three slight adjustments (about 10\%) for PCCs ELEVATION, HI and Arable have been implemented for two different catchments.

The resulting non-scaled SOF values for the optimum, regional and default parameter sets (see Section 3.2) for the eight validation catchments are given in Table 7. Validation shows that the regional parameter set in general performs dissatisfyingly. For 4 out of 8 validation catchments $R V_{\mathrm{E}}$ values as generated with 
the regional parameter set are comparable to the optimised SOF values. However, for the other four catchments the decrease in $R V_{\mathrm{E}}$ values from the optimised model to the regional model is very large, for example from $0.06 \%$ to $112.12 \%$ and from $-0.49 \%$ to $85.77 \%$. Thus, the regional model has difficulty in simulating the water balance. Concerning the calculated $N S$ values, for two validation catchments (i.e. 47008 and 53013) satisfying regionalised NS values are found that are comparable to optimum $N S$ values. For the remaining catchments the decrease in general is considerable, i.e. at least 0.14 . For the $N S_{\mathrm{H}}$ and $N S_{\mathrm{L}}$ values the decrease in model performance generated with the regional parameter set in general is larger, i.e. at least 0.41 . For most validation catchments negative optimised $N S_{\mathrm{H}}$ and $N S_{\mathrm{L}}$ values are generated indicating that the HBV model has difficulty in simulating high and low flows correctly. It should be noted that the SOFs for high and particularly low flows are primarily used to compare the model's ability to simulate high and low flow behaviour for different parameter sets to be used in the MOF. The absolute values of these SOFs should not be interpreted in the way regular $N S$ values are interpreted (e.g. a value above 0.6 is satisfying and a value of 0.9 is very good).

When comparing the regionalised SOF values of the eight validation catchments with the values generated by the default parameter set as given in Table 7, it is shown that both parameter sets perform comparatively. Out of a total of 32 generated regionalised SOF values, 13 values are better than the SOF values generated with

Table 7 Non-scaled SOF values for the optimum parameter set, the regional model and the default parameter set for eight validation catchments

\begin{tabular}{|c|c|c|c|c|c|}
\hline Catchment & Parameter set & $N S(-)$ & $R V_{\mathrm{E}}(\%)$ & $N S_{\mathrm{H}}(-)$ & $N S_{\mathrm{L}}(-)$ \\
\hline \multirow[t]{3}{*}{27034} & Optimum & 0.75 & -0.31 & -0.25 & -3.31 \\
\hline & Regional & 0.55 & -1.44 & -5.10 & -56.12 \\
\hline & Default & 0.62 & 1.05 & -0.30 & -224.59 \\
\hline \multirow[t]{3}{*}{27056} & Optimum & -0.01 & 2.99 & -2.80 & -4.12 \\
\hline & Regional & 0.08 & -12.29 & -3.28 & -13.12 \\
\hline & Default & -0.74 & 12.08 & -2.61 & -10.21 \\
\hline \multirow[t]{3}{*}{31010} & Optimum & 0.75 & -4.88 & -0.64 & -0.84 \\
\hline & Regional & 0.61 & -2.64 & -2.91 & -12.41 \\
\hline & Default & 0.72 & 3.23 & -1.10 & -8.35 \\
\hline \multirow[t]{3}{*}{38029} & Optimum & 0.65 & 0.06 & 0.27 & -21.26 \\
\hline & Regional & -0.04 & 112.12 & -0.14 & -336.46 \\
\hline & Default & 0.25 & 119.36 & -0.04 & -201.18 \\
\hline \multirow[t]{3}{*}{42008} & Optimum & 0.47 & -0.49 & -4.92 & -1.18 \\
\hline & Regional & -19.88 & 85.77 & -310.83 & -124.87 \\
\hline & Default & -36.59 & 85.66 & -308.23 & -139.45 \\
\hline \multirow[t]{3}{*}{47008} & Optimum & 0.85 & -1.86 & -2.19 & -2.69 \\
\hline & Regional & 0.83 & -1.47 & -3.46 & -70.17 \\
\hline & Default & 0.84 & 6.94 & -1.94 & -142.42 \\
\hline \multirow[t]{3}{*}{53013} & Optimum & 0.72 & -7.90 & -0.80 & -10.40 \\
\hline & Regional & 0.70 & -6.31 & -1.77 & -50.23 \\
\hline & Default & 0.79 & -6.35 & -0.60 & -20.97 \\
\hline \multirow[t]{3}{*}{60010} & Optimum & 0.76 & 11.12 & 0.27 & -0.69 \\
\hline & Regional & 0.45 & 21.34 & -0.15 & -1.41 \\
\hline & Default & -0.46 & 22.11 & -1.02 & -1.98 \\
\hline
\end{tabular}

Values of the regional model in italics are lower than the values for the default parameter set 
the default parameter set, whereas an improvement of model performance by the regional model was expected. For $R V_{\mathrm{E}}$, the regionalised and default values are comparable although for one catchment the performance is considerably better for the regional model. For the regionalised $N S$ values the default parameter set performs better for five out of eight validation catchments and actually indicates deterioration of results of the regional model. Additionally, for the remaining three validation catchments the model performance is disappointing (i.e. values of -19.88 , 0.08 and 0.45 ). With respect to $N S_{\mathrm{H}}$ the default parameter set performs better for seven out of eight validation catchments. The regional parameter set performs better for $N S_{\mathrm{L}}$ for four out of eight validation catchments as compared to the default parameter set. The performance of the default set in general is disappointing with values of -124.87 and -70.17 . There is only one validation catchment (60010) for which the regional parameter set performs better for all four SOFs as compared to the default parameter set.

Figure 2 shows the observed and modelled hydrograph with the regional and optimum parameter set for two validation catchments to illustrate performance of

(a)
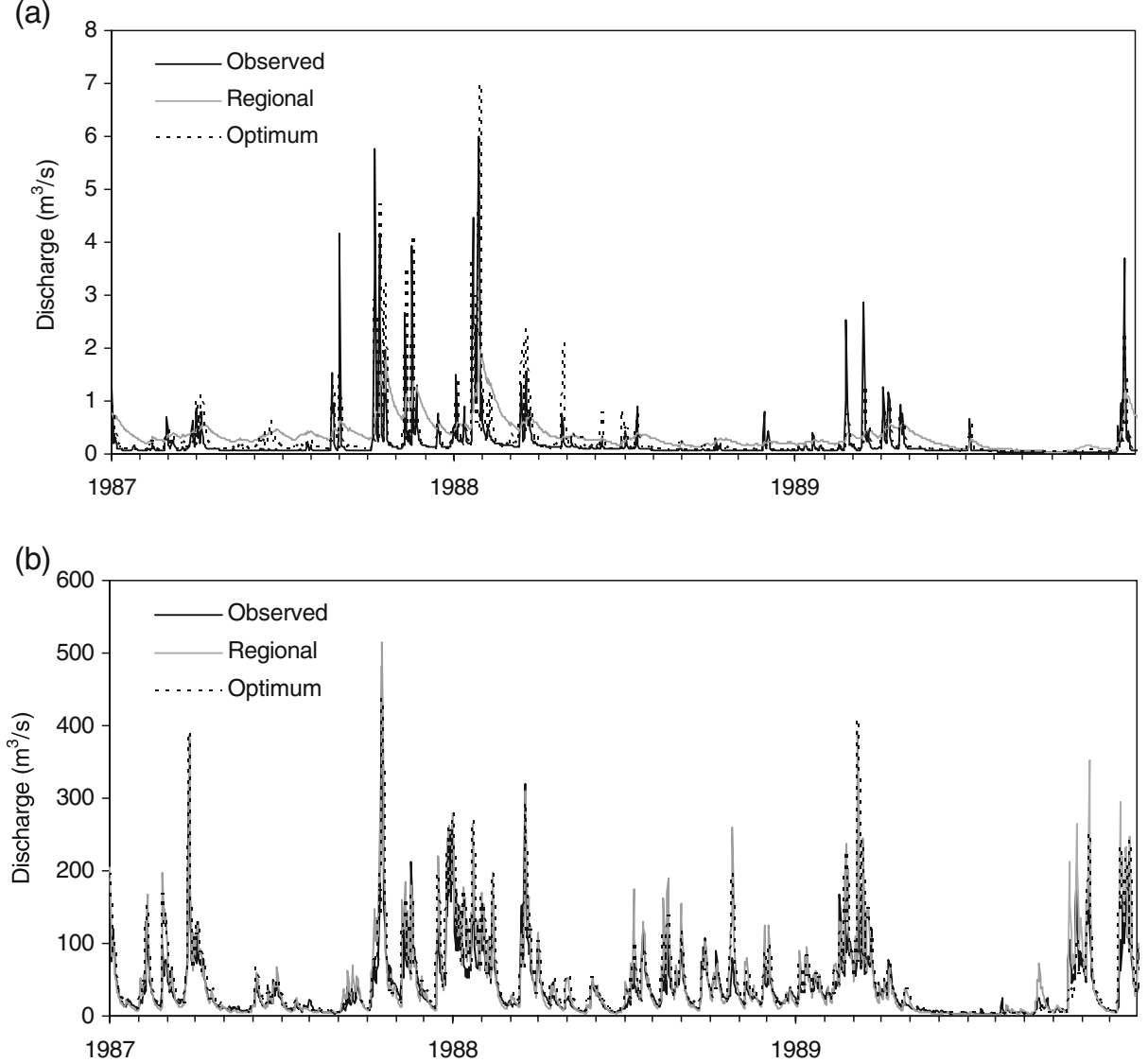

Fig. 2 Observed discharge and modelled discharge with regional and optimum parameter set for validation catchments 38029 (a) and 60010 (b) for the period 1987-1989 
Table 8 Non-scaled SOF values for the optimum parameter set, the regional model and the default parameter set for 18 non-satisfying calibration catchments with NS values above 0.6

\begin{tabular}{|c|c|c|c|c|c|}
\hline Catchment & Parameter set & $N S(-)$ & $R V_{\mathrm{E}}(\%)$ & $N S_{\mathrm{H}}(-)$ & $N S_{\mathrm{L}}(-)$ \\
\hline \multirow[t]{3}{*}{22001} & Optimum & 0.65 & -1.18 & -2.00 & -1.17 \\
\hline & Regional & 0.51 & -12.46 & -5.46 & -14.40 \\
\hline & Default & 0.63 & 3.32 & -2.23 & -13.31 \\
\hline \multirow[t]{3}{*}{22006} & Optimum & 0.63 & 2.07 & -0.88 & -2.47 \\
\hline & Regional & 0.22 & -14.36 & -8.90 & -1480.24 \\
\hline & Default & 0.62 & 24.94 & -0.77 & -902.41 \\
\hline \multirow[t]{3}{*}{23006} & Optimum & 0.72 & -1.89 & -1.76 & -2.12 \\
\hline & Regional & 0.48 & 0.65 & -10.50 & -3.09 \\
\hline & Default & 0.68 & 3.11 & -2.85 & -3.40 \\
\hline \multirow[t]{3}{*}{24004} & Optimum & 0.61 & -8.15 & -1.54 & -2.17 \\
\hline & Regional & 0.43 & -20.38 & -4.50 & -26.86 \\
\hline & Default & 0.59 & -10.55 & -1.87 & -4.88 \\
\hline \multirow[t]{3}{*}{25005} & Optimum & 0.69 & 2.54 & 0.26 & -1.59 \\
\hline & Regional & 0.65 & -12.53 & -0.56 & -5.48 \\
\hline & Default & 0.66 & 5.04 & -0.16 & -14.54 \\
\hline \multirow[t]{3}{*}{25006} & Optimum & 0.71 & -1.80 & -0.39 & -2.96 \\
\hline & Regional & 0.37 & -3.42 & -5.57 & -46.20 \\
\hline & Default & 0.60 & 1.11 & -0.53 & -217.84 \\
\hline \multirow[t]{3}{*}{27042} & Optimum & 0.67 & -2.98 & 0.12 & -0.42 \\
\hline & Regional & 0.57 & -15.03 & -0.76 & -11.57 \\
\hline & Default & 0.59 & -5.37 & -0.05 & -1.14 \\
\hline \multirow[t]{3}{*}{28008} & Optimum & 0.75 & -1.79 & 0.64 & -6.90 \\
\hline & Regional & 0.72 & -5.10 & 0.32 & -83.20 \\
\hline & Default & 0.59 & -1.28 & -0.30 & -23.57 \\
\hline \multirow[t]{3}{*}{30015} & Optimum & 0.68 & -1.21 & -2.77 & 0.24 \\
\hline & Regional & 0.49 & 29.40 & -0.70 & -33.42 \\
\hline & Default & -0.60 & 32.76 & -13.35 & -14.77 \\
\hline \multirow[t]{3}{*}{31025} & Optimum & 0.67 & -3.38 & -0.64 & -4.26 \\
\hline & Regional & 0.25 & -11.91 & -8.85 & -794.70 \\
\hline & Default & 0.57 & 23.05 & -1.42 & -429.47 \\
\hline \multirow[t]{3}{*}{32004} & Optimum & 0.65 & -4.10 & 0.27 & -0.04 \\
\hline & Regional & 0.43 & 0.58 & -4.24 & -76.68 \\
\hline & Default & 0.77 & 12.21 & 0.53 & -6.27 \\
\hline \multirow[t]{3}{*}{32006} & Optimum & 0.73 & -2.71 & 0.24 & -2.38 \\
\hline & Regional & 0.53 & -3.92 & -3.19 & -44.71 \\
\hline & Default & 0.68 & 23.42 & -0.41 & -9.36 \\
\hline \multirow[t]{3}{*}{33029} & Optimum & 0.70 & -0.41 & -0.66 & -2.20 \\
\hline & Regional & -0.55 & 55.33 & -9.55 & -338.11 \\
\hline & Default & -0.76 & 62.23 & -13.46 & -315.50 \\
\hline \multirow[t]{3}{*}{36003} & Optimum & 0.69 & 1.11 & 0.81 & -1.61 \\
\hline & Regional & 0.45 & 44.81 & 0.55 & -5.96 \\
\hline & Default & 0.66 & 39.06 & 0.77 & -7.31 \\
\hline \multirow[t]{3}{*}{49002} & Optimum & 0.86 & -7.32 & 0.47 & -13.77 \\
\hline & Regional & 0.44 & -24.36 & -1.09 & -14.26 \\
\hline & Default & 0.08 & -10.69 & -0.68 & -48.87 \\
\hline \multirow[t]{3}{*}{53017} & Optimum & 0.80 & -4.54 & 0.07 & -2.56 \\
\hline & Regional & 0.83 & -0.94 & 0.26 & -10.94 \\
\hline & Default & 0.85 & 0.50 & 0.42 & -31.13 \\
\hline
\end{tabular}


Table 8 (continued)

\begin{tabular}{llccrr}
\hline Catchment & Parameter set & $N S(-)$ & $R V_{\mathrm{E}}(\%)$ & $N S_{\mathrm{H}}(-)$ & \multicolumn{1}{c}{$N S_{\mathrm{L}}(-)$} \\
\hline 62001 & Optimum & 0.84 & -6.21 & 0.01 & 0.37 \\
& Regional & 0.66 & -8.74 & 0.37 & 0.38 \\
& Default & 0.50 & -6.84 & 0.15 & -6.34 \\
67018 & Optimum & 0.73 & -4.71 & -1.47 & 0.70 \\
& Regional & 0.70 & -5.77 & -1.58 & -0.63 \\
& Default & 0.67 & -6.37 & -1.78 & 0.87 \\
\hline
\end{tabular}

Values of the regional model in italics are lower than the values for the default parameter set

the regional model. For one catchment (38029, see Table 7) the regional parameter set results in very poor performance while the optimum parameter set shows a reasonable simulation. For the other catchment (60010) the regional parameter set shows performance in line with the optimum performance. The regional model clearly does not capture the discharge peaks and largely overestimates the discharge for average and low flow periods (see also the $R V_{\mathrm{E}}$ value in Table 7) for catchment 38029. This is probably caused by the small $A L F A$ and $K_{\mathrm{f}}$ values as predicted by the regional model compared to the optimum values for these parameters. The original $K_{\mathrm{f}}$ value as predicted by the regional model was negative and had to be adjusted to the minimum $K_{\mathrm{f}}$ value as obtained in the calibration. The regionalisation relationship for ALFA can be (partially) questioned based on hydrological interpretation (see Table 6). Although the regional model slightly overestimates discharge variability and peaks for catchment 60010, the general discharge behaviour is well simulated and comparable with the discharge behaviour as simulated with the optimum parameter set.

An additional validation is done using a sub-set of the non-satisfying calibration catchments with a NS value above 0.6. This resulted in 18 additional catchments available for validation since these catchments have not been used for calibration purposes (see Section 4.1). Table 8 shows the resulting non-scaled SOF values for the optimum, regional and default parameter sets for these catchments. The additional validation runs for 18 catchments generally shows similar results as for the validation with 8 catchments. For 6 out of 18 catchments for $N S$ and for 8 out of 18 catchments for $R V_{\mathrm{E}}$, SOF values as generated with the regional parameter set are comparable to the optimised SOF values. Results for $N S_{\mathrm{H}}$ and $N S_{\mathrm{L}}$ are similar or poorer as compared to the results for the validation catchments. Default sets perform equally or slightly better than regional parameter sets. Out of a total of 72 generated regionalised SOF values, 26 values are better than the SOF values generated with the default parameter sets. These additional validation results are in line with the original validation results and indicate dissatisfying performance of the regional model.

\section{Discussion}

In this study, 31 out of 48 catchments could not be satisfactory calibrated by very stringent criteria and are ignored for establishing regional relationships that make 
up the regional model. Model calibration was performed through MCS on four complementary objective functions that independently have been optimised. For runoff simulation the HBV model has been selected as also applied by for instance Seibert (1999) and Merz and Blöschl (2004).

\subsection{Calibration}

As described, in this work calibration and validation results in general were not satisfying and regionalised model parameters did not allow to accurately simulate a large number of catchments. Clear reasons for disappointing model performance could not be identified, although possible causes relate to the input of inaccurate meteorological forcing data, inadequate multi-objective optimization, insufficiencies in the model structure of the HBV model, inadequate selection of PCCs and weakly defined regionalisation relations.

Selection of calibration catchments to be used for regionalisation is based on predefined values of the objective functions that assess the overall fit of observed and simulated hydrographs. By (very) constraining performance criteria of $N S>0.75$ and $R V_{\mathrm{E}}$ of $<5 \%$ this selection resulted in only 17 catchments and could suggest that the HBV model has some insufficiencies. It must be noted however that successful applications are reported in literature in a wide range of climatic and topographic settings (see Lidén and Harlin 2000; Booij 2005; Akhtar et al. 2008, 2009; Wale et al. 2009). Thus the small number could indicate that, in particular, meteorological forcing by precipitation and evapotranspiration is poorly represented. An inappropriate model structure as well as poor representation of meteorological forcing are also identified in Young (2006) as possible cause of disappointing results of a regionalisation approach for 260 catchments in the UK.

\subsection{Establishing the Regional Model}

Principle to our regionalisation procedure is that PCCs to be used in the regional model are assumed to be of relevance to describe catchment runoff. By regression analysis, in this work it is shown that for only few PCCs statistically significant relationships could be established with selected HBV model parameters. Although each of the PCCs has some hydrological relevance, effects on how these PCCs affect quick flow and how much runoff is produced through saturation and infiltration excess mechanisms could not be shown. In using PCCs in regionalisation it must be realised that detailed real world information that largely affects runoff dynamics is ignored (as in the model). Duan et al. (2006) describe results of the MOPEX experiment and indicates that much research is needed to understand how model parameters relate to basin characteristics. Also it is described that 'observable' characteristics, that also are used in this study, may not be the most relevant descriptors of factors that control runoff production and runoff behaviour. In this research however we were not able to prove ineffectiveness of selected PCCs since such would require that effects of selected PCCs on runoff prediction can be isolated. Possibly the limited hydrological interpretability of the PCC causes that PCCs are not effective for all catchments.

Application of the regional model to eight validation catchments indicated disappointing performance and the established model parameter sets could not satisfactory predict runoff. An additional validation using a sub-set of the non-satisfying 
calibration catchments indicated similar results. For some catchments established parameter values fall outside earlier established minimum or maximum values. In the procedure it appears that assumed relationships between model parameters and PCCs are weak which results in unrealistic parameter values. As such the validity of the established regionalisation relations can be questioned and predictive capability only is poor. Overall it can be concluded that simulation results from regional and default parameter sets are comparable, which indicate that the established regional model has no universal validity for the catchments throughout the UK. Such is also shown in Young (2006) where it is described that catchments in the south of the UK are dominated by their groundwater flow regime and that for these catchments the water balance could not be closed. In the same work, for catchments towards the east coast of Scotland that are considered 'dry', the regionalisation failed since precipitation input is very poor due to a sparse rain gauge network. Similar conclusions in this paper cannot be drawn by the relatively small number of catchments used for validation.

\subsection{Catchment Variability}

In the regionalisation approach in this study it is assumed that optimised model parameters that represent certain catchment characteristics are applicable to other catchments as well in case catchment settings are comparable. Such settings, however, always are subject to variability and important is the question to which extent variability favours regionalisation. Little variation implies little hydrologic diversity that does allow establishment of strong regional relationships applicable to a limited number of catchments, while too much variation may result in weak relationships (more generally applicable). In Seibert (1999) a successful application of the HBV model is described for some 11 catchments that are characterised by only little variation in settings. Haberlandt et al. (2001) favour the assumption of large variability and a clear range of different conditions is advocated as basis for regionalisation. Work by Young (2006) on 260 catchments distributed across the entire UK showed that regionalisation in general was successful although results also indicate failure for catchments under dry climatic settings. Our approach in general was not successful although regionalisation was based on optimal parameter sets as defined by four objective functions. Possibly the entire data set carries too much variability to be effectively used for regionalisation. Differences in the above mentioned approaches are the procedure to select optimal parameters and the selected PCCs. This study only used PCCs from the National River Flow Archive that are available through CSI (2009). Concluding that PCCs are inappropriate or that optimal parameter sets are wrongly defined cannot be simply reasoned for. It must be noted that the base flow index as effective PCC in Young (2006), Kay et al. (2006), McIntyre et al. (2005) and Wagener and Wheater (2006) was not used in this study, but obviously has (very) positively affected the outcomes of these works. The latter work considered only 10 catchments in south east England with, presumably, much less variability. Also Wagener and Wheater (2006) report on statistical regionalisation while again a number of different PCCs are selected. Results from that work with a simple conceptual model structure are satisfying although it is stated that the approach is unlikely to be robust because of the small number of catchments. 


\section{Conclusions}

In this study the classical approach of regionalisation is applied to a set of 56 catchments in England and Wales in order to assess predictive capability of a regional model in simulating runoff at assumed ungauged catchments. For runoff simulation at calibration and validation catchments the HBV model is used. Optimal parameter sets are established by considering a combination of four single objective functions and MCS. Our approach was to establish relationships between optimised parameter sets and PCCs, and for six out of seven selected model parameters statistically significant relationships could be derived three of which are hydrologically plausible. For the seventh model parameter a default parameter value is used to complete the regional model.

Validation of the regional model at eight catchments revealed that the performance is not satisfactory. The difference in performance of the regional model and the optimum parameter set was larger than expected for most catchments. Also some default parameter values perform better than regionalised parameter values. Results show that default parameter sets outperformed regional parameter sets for 19 out of 32 single objective function values for the validation catchments. Similar results were obtained by additional validation runs using a sub-set of catchments not used in the regionalisation. It is concluded that regionalisation in this research was not successful and that predictive capability of the established regional model could not be improved. Identification of causes for the disappointing performance of the proposed regionalisation approach indicated that performance was due to a number of causes. Quantification of each of these causes however was not possible due to the complexity and interdependencies of causes.

Further research on the classical approach of regionalisation should focus on the relation between model parameters and PCCs. Different (local) model structures with the same set of PCCs and vice versa, different PCCs for the same model structure could be tested to identify appropriate model structures and accompanying PCCs when using the classical approach. Moreover, PCCs and model parameters could be more adapted to each other by constructing PCCs describing the runoff formation process as simulated by the model, and by adapting or developing model structures incorporating observable 'PCCs'. Alternatively, other regionalisation approaches can obviously be tested and compared to the classical approach using the same model structure for similar climatic and geographical conditions.

Acknowledgements The authors are grateful to the British Atmospheric Data Centre which provided us with access to the Met Office Land Surface Observation Stations Data, the Top Down modelling Working Group within the PUB initiative for the hydrometric data and the National River Flow Archive for all physiographic data.

Open Access This article is distributed under the terms of the Creative Commons Attribution Noncommercial License which permits any noncommercial use, distribution, and reproduction in any medium, provided the original author(s) and source are credited.

\section{References}

Abdulla F, Eshtawi T, Assaf H (2009) Assessment of the impact of potential climate change on the water balance of a semi-arid watershed. Water Resour Manag 23:2051-2068 
Akhtar M, Ahmad N, Booij MJ (2008) The impact of climate change on the water resources of Hindukush-Karakorum-Himalaya region under different glacier coverage scenarios. J Hydrol 355:148-163

Akhtar M, Ahmad N, Booij MJ (2009) Use of regional climate model simulations as input for hydrological models for the Hindukush-Karakorum-Himalaya region. Hydrol Earth Syst Sci 13:1075-1089

Ao T, Ishidaira H, Takeuchi K, Kiem AS, Yoshitari J, Fukami K, Magome J (2006) Relating BTOPMC model parameters to physical features of MOPEX basins. J Hydrol 320:84-102

BADC (2009) British atmospheric data centre. http://badc.nerc.ac.uk. Accessed 17 November 2009

Bergström S (1990) Parameter values for the HBV model in Sweden (in Swedish). Technical Report no. 28. SMHI, Norrköping

Bergström S (1995) The HBV model. In: Singh VP (ed) Computer models of watershed hydrology. Water Resources Publications, Highlands Ranch, pp 443-476

Beven K, Binley A (1992) The future of distributed models: model calibration and uncertainty prediction. Hydrol Process 6:279-298

Blöschl G, Sivapalan M (1995) Scale issues in hydrological modelling: a review. Hydrol Process 9:251-290

Booij MJ (2005) Impact of climate change on river flooding assessed with different spatial model resolutions. J Hydrol 303:176-198

CSI (2009) Catchment spatial information. http://www.ceh.ac.uk/data/nrfa/catchment_spatial_ information.html. Accessed 17 November 2009

Cutore P, Cristaudo G, Campisano A, Modica C, Cancelliere A, Rossi G (2007) Regional models for the estimation of streamflow series in ungauged basins. Water Resour Manag 21:789-800

Data60UK (2009) Eleven-year records (1980-1990) of continuous daily catchment precipitation and mean streamflow for 61 catchments throughout England and Wales. http://www.nwl.ac.uk/ ih/nrfa/pub/index.html. Accessed 17 November 2009

De Vos NJ, Rientjes THM (2007) Multi-objective performance comparison of an artificial neural network and a conceptual rainfall-runoff model. Hydrol Sci J 52:397-413

De Vos NJ, Rientjes THM (2008) Multi-objective training of artificial neural networks for rainfallrunoff modeling. Water Resour Res 44:W08434

Diermanse FLM (2001) Physically based modelling of rainfall-runoff processes. PhD thesis. Delft University Press, Delft

Duan Q, Schaake J, Andréassian V, Franks S, Goteti G, Gupta HV, Gusev YM, Habets F, Hall A, Hay L, Hogue T, Huang M, Leavesley G, Liang X, Nasonova ON, Noilhan J, Oudin L, Sorooshian S, Wagener T, Wood EF (2006) Model parameter estimation experiment (MOPEX): an overview of science strategy and major results from the second and third workshops. J Hydrol 320:3-17

Engeland K, Hisdal H (2009) A comparison of low flow estimates in ungauged catchments using regional regression and the HBV-model. Water Resour Manag 23:2567-2586

Gupta HV, Sorooshian S, Yapo PO (1998) Toward improved calibration of hydrologic models: multiple and noncommensurable measures of information. Water Resour Res 34:751-763

Gupta HV, Wagener T, Liu Y (2008) Reconciling theory with observations: elements of a diagnostic approach to model evaluation. Hydrol Process 22:3802-3813

Haberlandt U, Klöcking B, Krysanova V, Becker A (2001) Regionalisation of the base flow index from dynamically simulated flow components - a case study in the Elbe River Basin. J Hydrol 248:35-53

Harlin J, Kung C (1992) Parameter uncertainty and simulation of design floods in Sweden. J Hydrol 137:209-230

Hundecha Y, Bárdossy A (2004) Modelling of the effect of land use change on the runoff generation of a river basin through parameter regionalization of a watershed model. J Hydrol 292: 281-295

Jakeman AJ, Hornberger GM (1993) How much complexity is warranted in a rainfall-runoff model? Water Resour Res 29:2637-2649

Jakeman AJ, Littlewood IG, Whitehead PG (1990) Computation of the instantaneous unit hydrograph and identifiable component flows with application to two small upland catchments. J Hydrol 117:275-300

Kay AL, Jones DA, Crooks SM, Calver A, Reynard NS (2006) A comparison of three approaches to spatial generalization of rainfall-runoff models. Hydrol Process 20:3953-3973

Killingtveit A, Sælthun NR (1995) Hydropower development: hydrology. Technical report. Norwegian Institute of Technology, Oslo 
Khu ST, Madsen H (2005) Multiobjective calibration with Pareto preference ordering: an application to rainfall-runoff model calibration. Water Resour Res 41:W03004

Klemeš V (1986) Operational testing of hydrological simulation models. Hydrol Sci J 31:13-24

Kokkonen T, Jakeman A, Young P, Koivusalo H (2003) Predicting daily flows in ungauged catchments: model regionalization from catchment descriptors at the Coweeta Hydrologic Laboratory, North Carolina. Hydrol Process 17:2219-2238

Lidén R, Harlin J (2000) Analysis of conceptual rainfall-runoff modelling performance in different climates. J Hydrol 238:231-247

Lindström G, Johansson B, Persson M, Gardelin M, Bergström S (1997) Development and test of the distributed HBV-96 hydrological model. J Hydrol 201:272-288

Madsen H (2000) Automatic calibration of a conceptual rainfall-runoff model using multiple objectives. J Hydrol 235:276-288

McIntyre N, Lee H, Wheater H, Young A (2005) Ensemble predictions of runoff in ungauged catchments. Water Resour Res 41:W12434

Merz R, Blöschl G (2004) Regionalisation of catchment model parameters. J Hydrol 287:95-123

Moore RJ (1985) The probability-distributed principle and runoff production at point and basin scales. Hydrol Sci J 30:273-297

Moore RJ (1999) Real-time flood forecasting systems: perspectives and prospects. In: Casale R, Margottini C (eds) Floods and landslides: integrated risk assessment. Springer, Berlin, pp 147-189

Nash JE, Sutcliffe JV (1970) River flow forecasting through conceptual models. Part I - A discussion of principles. J Hydrol 10:282-290

NRFA (2009) National River Flow Archive. http://www.ceh.ac.uk/data/nrfa/index.html. Accessed 17 November 2009

Oudin L, Andréassian V, Perrin C, Michel C, Le Moine N (2008) Spatial proximity, physical similarity, regression and ungaged catchments: a comparison of regionalization approaches based on 913 French catchments. Water Resour Res 44:W03413

Parajka J, Blöschl G, Merz R (2007) Regional calibration of catchment models: potential for ungauged catchments. Water Resour Res 43:W06406

Sefton CEM, Boorman DB (1997) A regional investigation of climate change impacts on UK streamflows. J Hydrol 195:26-44

Sefton CEM, Howarth SM (1998) Relationships between dynamic response characteristics and physical descriptors of catchments in England and Wales. J Hydrol 211:1-16

Seibert J (1997) Estimation of parameter uncertainty in the HBV model. Nord Hydrol 28:4-5

Seibert J (1999) Regionalisation of parameters for a conceptual rainfall-runoff model. Agric For Meteorol 98-99:279-293

Shaw EM (1994) Hydrology in practice, 3rd edn. Chapman \& Hall, London

Sivapalan M, Takeuchi K, Franks SW, Gupta VK, Karambiri H, Lakshmi V, Liang X, McDonnell JJ, Mendiondo EM, O'Connell PE, Oki T, Pomeroy JW, Schertzer D, Uhlenbrook S, Zehe E (2003) IAHS decade on predictions in ungauged basins (PUB), 2003-2012: shaping an exciting future for the hydrological sciences. Hydrol Sci J 48:857-880

SMHI (1999) Integrated hydrologic modelling system (IHMS). Manual version 4.3. SMHI, Norrköping

Strahler AN (1952) Hypsometric (area-altitude) analysis of erosional topography. Geol Soc Amer Bull 63:1117-1141

Tang Y, Reed P, Wagener T (2006) How effective and efficient are multiobjective evolutionary algorithms at hydrological model calibration? Hydrol Earth Syst Sci 10:289-307

Velner RGJ (2000) Rainfall-runoff modelling of the Ourthe catchment with the HBV model. A study for extension of the lead time for flood forecasting in the Meuse (in Dutch). RIZA working document 2000.091X. Wageningen University, Wageningen

Verbunt M, Zwaaftink MG, Gurtz J (2005) The hydrological impact of land cover changes and hydropower stations in the Alpine Rhine basin. Ecol Model 187:71-84

Wagener T, Wheater HS (2006) Parameter estimation and regionalization for continuous rainfallrunoff models including uncertainty. J Hydrol 320:132-154

Wagener T, Lees MJ, Wheater HS (2002) A toolkit for the development and application of parsimonious hydrological models. In: Singh VP, Frevert D (eds) Mathematical models of large watershed hydrology, vol 1. Water Resources Publications, Highlands Ranch, pp 87-136

Wagener T, Wheater HS, Gupta HV (2003) Identification and evaluation of watershed models. In: Duan Q, Gupta HV, Sorooshian S, Rousseau AN, Turcotte R (eds) Calibration of watershed models. Water Science and Application 6, American Geophysical Union, pp 29-47 
Wale A, Rientjes THM, Gieske ASM, Getachew HA (2009) Ungauged catchment contributions to Lake Tana's water balance. Hydrol Process 23:3682-3693

Yadav M, Wagener T, Gupta H (2007) Regionalization of constraints on expected watershed response behavior for improved predictions in ungauged basins. Adv Water Resour 30:1756-1774

Yapo PO, Gupta HV, Sorooshian S (1998) Multi-objective global optimization for hydrologic models. J Hydrol 204:83-97

Young AR (2006) Stream flow simulation within UK ungauged catchments using a daily rainfallrunoff model. J Hydrol 320:155-172

Zhang YQ, Chiew FHS (2009) Relative merits of different methods for runoff predictions in ungauged catchments. Water Resour Res 45:W07412 